\title{
Second Messengers
}

\author{
Alexandra C. Newton ${ }^{1}$, Martin D. Bootman ${ }^{2}$, and John D. Scott ${ }^{3}$ \\ ${ }^{1}$ Department of Pharmacology, University of California at San Diego, La Jolla, California 92093 \\ ${ }^{2}$ Department of Life, Health and Chemical Sciences, The Open University, Walton Hall, Milton Keynes MK7 6AA, \\ United Kingdom \\ ${ }^{3}$ Department of Pharmacology, Howard Hughes Medical Institute, University of Washington School of Medicine, \\ Seattle, Washington 98195 \\ Correspondence: anewton@ucsd.edu
}

\section{SUMMARY}

Second messengers are small molecules and ions that relay signals received by cell-surface receptors to effector proteins. They include a wide variety of chemical species and have diverse properties that allow them to signal within membranes (e.g., hydrophobic molecules such as lipids and lipid derivatives), within the cytosol (e.g., polar molecules such as nucleotides and ions), or between the two (e.g., gases and free radicals). Second messengers are typically present at low concentrations in resting cells and can be rapidly produced or released when cells are stimulated. The levels of second messengers are exquisitely controlled temporally and spatially, and, during signaling, enzymatic reactions or opening of ion channels ensure that they are highly amplified. These messengers then diffuse rapidly from the source and bind to target proteins to alter their properties (activity, localization, stability, etc.) to propagate signaling.

\section{Outline}
1 Introduction
2 Cyclic nucleotides
3 Lipid and lipid-derived second messengers

4 lons as intracellular messengers

5 Concluding remarks

References

Editors: Lewis Cantley, Tony Hunter, Richard Sever, and Jeremy Thorner

Additional Perspectives on Signal Transduction available at www.cshperspectives.org 


\section{INTRODUCTION}

Signals received by receptors at the cell surface or, in some cases, within the cell are often relayed throughout the cell via generation of small, rapidly diffusing molecules referred to as second messengers. These second messengers broadcast the initial signal (the "first message") that occurs when a ligand binds to a specific cellular receptor (see Heldin et al. 2014); ligand binding alters the protein conformation of the receptor such that it stimulates nearby effector proteins that catalyze the production or, in the case of ions, release or influx of the second messenger. The second messenger then diffuses rapidly to protein targets elsewhere within the cell, altering the activities as a response to the new information received by the receptor. Three classic second messenger pathways are illustrated in Figure 1: (1) activation of adenylyl cyclase by G-protein-coupled receptors (GPCRs) to generate the cyclic nucleotide second messenger $3^{\prime}-5^{\prime}$-cyclic adenosine monophosphate (cAMP); (2) stimulation of phosphoinositide 3-kinase (PI3K) by growth factor receptors to generate the lipid second mes- senger phosphatidylinositol 3,4,5-trisphosphate $\left(\mathrm{PIP}_{3}\right)$; and (3) activation of phospholipase C by GPCRs to generate the two second messengers membrane-bound messenger diacylglycerol (DAG) and soluble messenger inositol 1,4,5-trisphosphate $\left(\mathrm{IP}_{3}\right)$, which binds to receptors on subcellular organelles to release calcium into the cytosol. The activation of multiple effector pathways by a single plasma membrane receptor and the production of multiple second messengers by each effector can generate a high degree of amplification in signal transduction, and stimulate diverse, pleiotropic, responses depending on the cell type.

Second messengers fall into four major classes: cyclic nucleotides, such as cAMP and other soluble molecules that signal within the cytosol; lipid messengers that signal within cell membranes; ions that signal within and between cellular compartments; and gases and free radicals that can signal throughout the cell and even to neighboring cells. Second messengers from each of these classes bind to specific protein targets, altering their activity to relay downstream signals. In many cases, these targets are enzymes

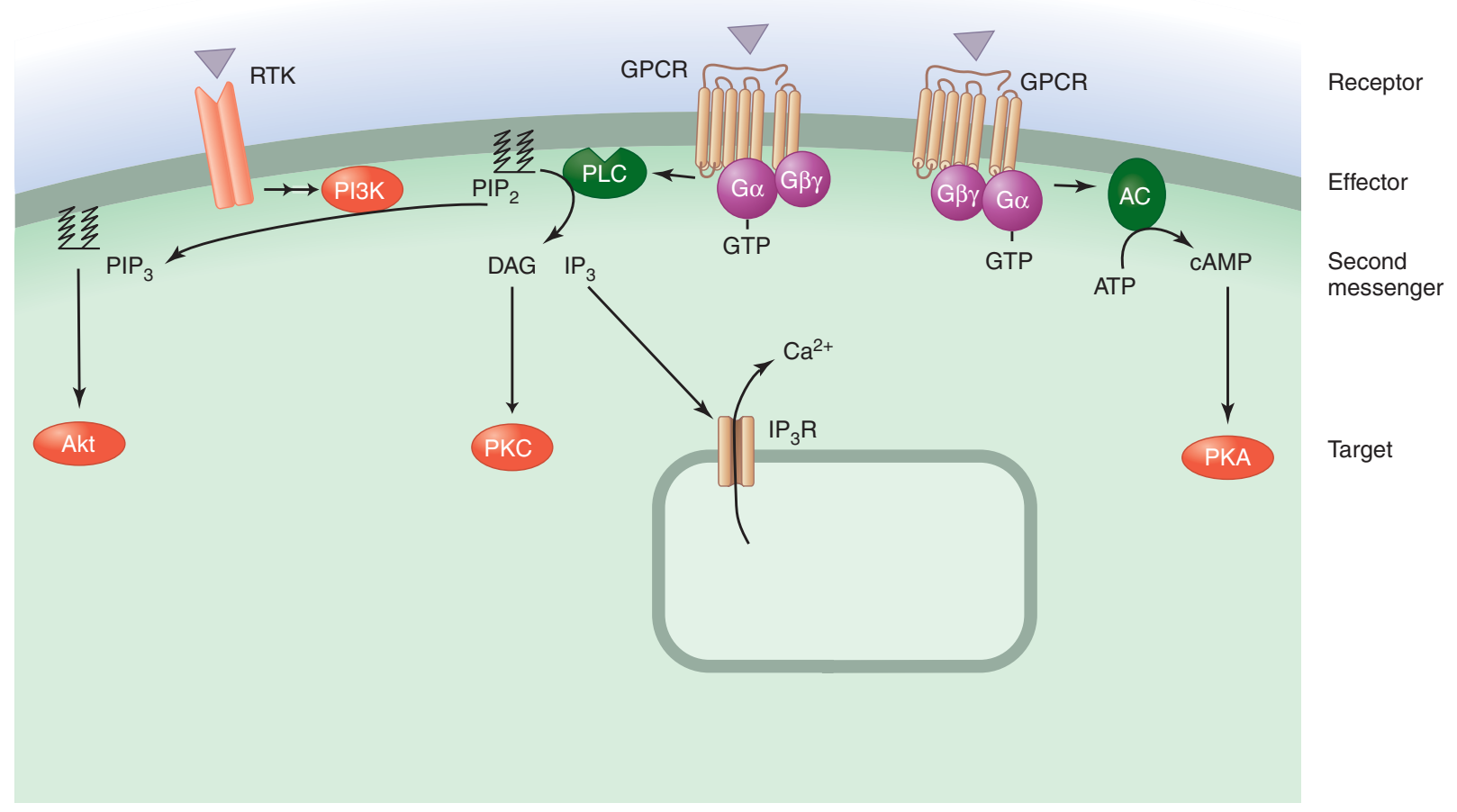

Figure 1. Second messengers disseminate information received from cell-surface receptors. Indicated are three examples of a receptor activating an effector to produce a second messenger that modulates the activity of a target. On the right, binding of agonists to a GPCR (the receptor) can activate adenylyl cyclase (the effector) to produce cAMP (the second messenger) to activate protein kinase A (PKA; the target). On the left, binding of growth factors to a receptor tyrosine kinase (RTK; the receptor) can activate PI3K (the effector) to generate PIP $_{3}$ (the second messenger), which activates Akt (the target). In the center, binding of ligands to a GPCR (receptor) activates phospholipase C (PLC; the effector), to generate two second messengers, DAG and $\mathrm{IP}_{3}$, which activate protein kinase $\mathrm{C}$ (PKC; the target) and release calcium from intracellular stores, respectively. 
whose catalytic activity is modified by direct binding of the second messengers. The activation of multiple target enzymes by a single second messenger molecule further amplifies the signal.

Second messengers are not only produced in response to extracellular stimuli, but also in response to stimuli from within the cell. Moreover, their levels are exquisitely controlled by various homeostatic mechanisms to ensure precision in cell signaling. Indeed, dysregulation of the second messenger output in response to a particular agonist can result in cell/organ dysfunction and disease. For example, chronic exposure to cAMP in the heart results in an uncontrolled and asynchronous growth of cardiac muscle cells called pathological hypertrophy. This early stage heart disease presents as a thickening of the heart muscle (myocardium), a decrease in size of the chamber of the heart, and changes in contractility. Because such prolonged exposure to second messengers has deleterious effects, specific enzymes, channels, and buffering proteins exist to rapidly remove second messengers, either by metabolizing them or sequestering them away from target molecules.

\section{CYCLIC NUCLEOTIDES}

\section{1 cAMP and a Major Target, PKA}

The "fight or flight" mechanism, more accurately referred to as the adrenal response, prepares the body for situations of extreme stress. Release of the hormone epinephrine, also known as adrenaline, from the adrenal gland into the blood rapidly triggers vital cellular and physiological reactions that prepare the body for intense physical activity. One of the most important effects is the breakdown of glycogen into glucose to fuel muscles (Sutherland 1972).

Earl Sutherland first showed that epinephrine bound to cell-surface receptors stimulates membrane-associated adenylyl cyclases to synthesize the chemical messenger cAMP. Martin Rodbell and Alfred Gillman then discovered that G-protein subunits are the intermediates that shuttle between receptors and a family of eight adenylyl cyclase isoforms in the plasma membrane. Each $G$ protein is a trimer consisting of $G \alpha, G \beta$, and $G \gamma$ subunits. The $G \alpha$ subunits in the $G$ proteins $G_{s}$ and $G_{i}$ are distinct and provide the specificity for activation and inhibition of adenylyl cyclase, respectively. $G_{s}$ and $G_{i}$ can thus couple binding of ligands to GPCRs with either activation or inhibition of adenylyl cyclase, depending on the receptor type. This increases or reduces production of cAMP, which diffuses from the membrane into the cell. Edwin Krebs and Edmund Fischer later found that a principal task of cAMP is to stimulate protein phosphorylation (Fischer and Krebs 1955), ultimately showing cAMP-dependent protein ki- nase (also known as protein kinase A, PKA) is responsible (Krebs 1993; Gilman 1995).

PKA is the major target for cAMP (see Fig. 2) (SassoneCorsi 2012). It is a heterotetramer consisting of two regulatory $(\mathrm{R})$ subunits that maintain two catalytic $(\mathrm{C})$ subunits in an inhibited state. When cAMP levels are low, the PKA holoenzyme is dormant; however, when cAMP levels are elevated, two molecules bind in a highly cooperative manner to each $R$ subunit, causing a conformational change that releases the active $C$ subunits (Taylor et al. 2012). In humans, four genes encode $\mathrm{R}$ subunits ( $\mathrm{RI} \alpha, \mathrm{RI} \beta, \mathrm{RII} \alpha$, and RII $\beta$ ) and two genes encode $C$ subunits ( $C \alpha$ and $C \beta$ ), combinations of which are expressed in most, if not all, tissues. The C subunits of PKA phosphorylate serine or threonine residues on target substrates, typically within the sequence $\mathrm{RRxS} / \mathrm{T} \Phi$, in which $\Phi$ is an aliphatic hydrophobic residue or an aromatic residue (Kemp et al. 1976). Around 300-500 distinct intracellular proteins can be phosphorylated by PKA in a typical cell. These include glycogen phosphorylase as part of the fight-or-flight mechanism. Active phosphorylase catalyzes the production of glucose 1-phosphate, a metabolic intermediate that is ultimately converted into other modified sugars that are used in various aspects of cellular catabolism and ATP production (see Hardie 2012). On its release from the PKA holoenzyme, the $\mathrm{C}$ subunit of PKA can diffuse into the nucleus, where it phosphorylates transcription factors such as the cAMP-response-elementbinding protein. cAMP can thereby ultimately influence transcriptional activation and reprogramming of the cell.

Additional layers of regulation ensure that PKA phosphorylates the correct proteins at the right time. For example, prostaglandin E1 and epinephrine both produce similar increases in cAMP and PKA activity in the heart, but only epinephrine increases glycogen phosphorylase activity. This is achieved in part through attachment of PKA to subcellular structures via interactions between $\mathrm{R}$ subunits and A-kinase-anchoring proteins (AKAPs) (Wong and Scott 2004). Anchoring of PKA to subcellular structures by AKAPs is a means to limit the range of action of PKA and avert the indiscriminate transmission of these responses throughout the cell.

A typical cell expresses 10-15 different AKAPs. These proteins all contain an amphipathic-helix motif that binds to a docking and dimerization domain formed by the $\mathrm{R}$ subunits of PKA and targeting domains that tether the AKAPs to intracellular membranes or organelles. AKAPs promote signaling efficacy by placing PKA near preferred substrates and insulating different anchored PKA complexes from one another (Scott and Pawson 2009). Most AKAPs also organize other signaling proteins, such as GPCRs, GTPases, protein phosphatases, phosphodiesterase (PDE), and other protein kinases. 


\section{A.C. Newton et al.}

A

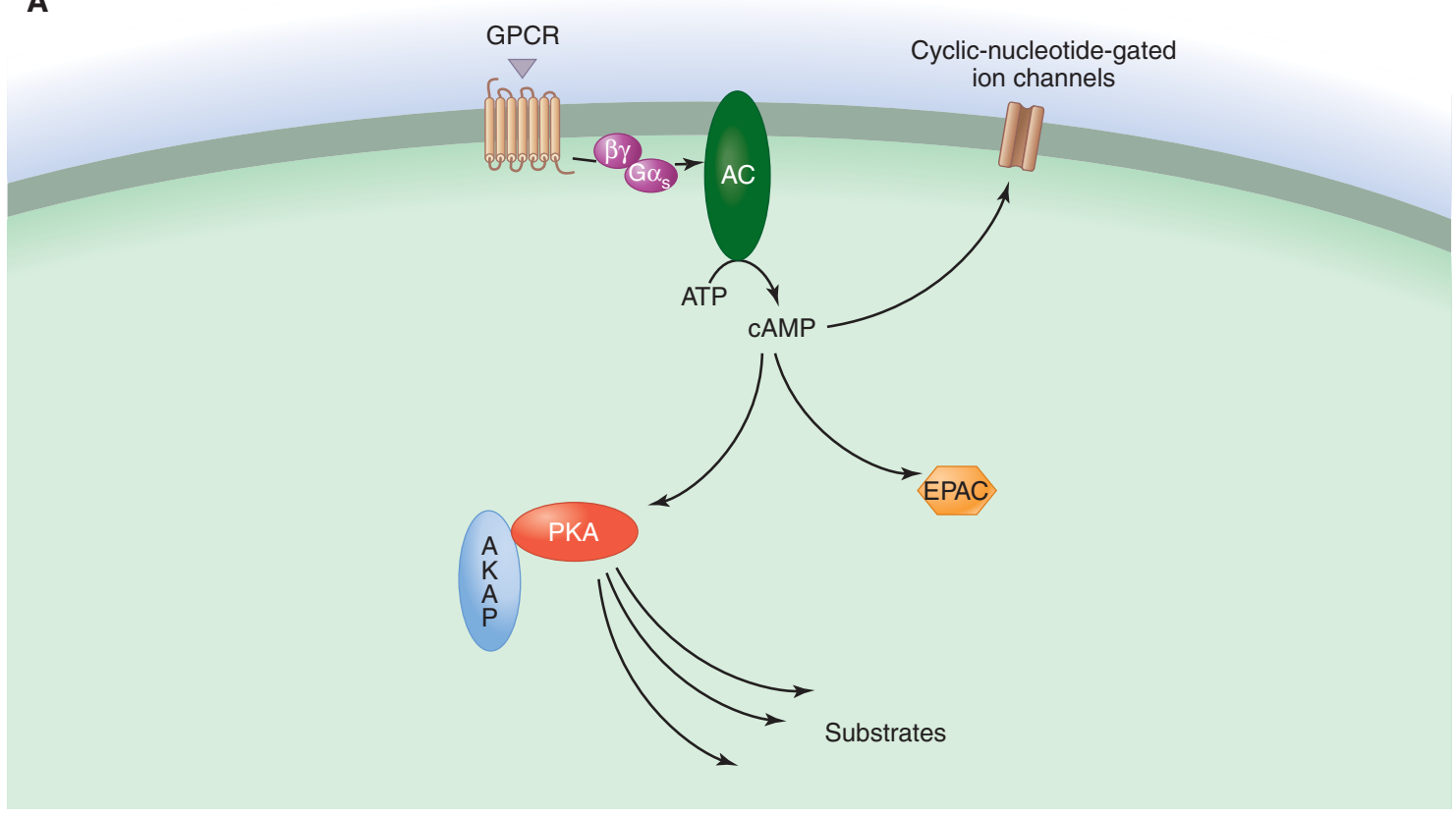

B

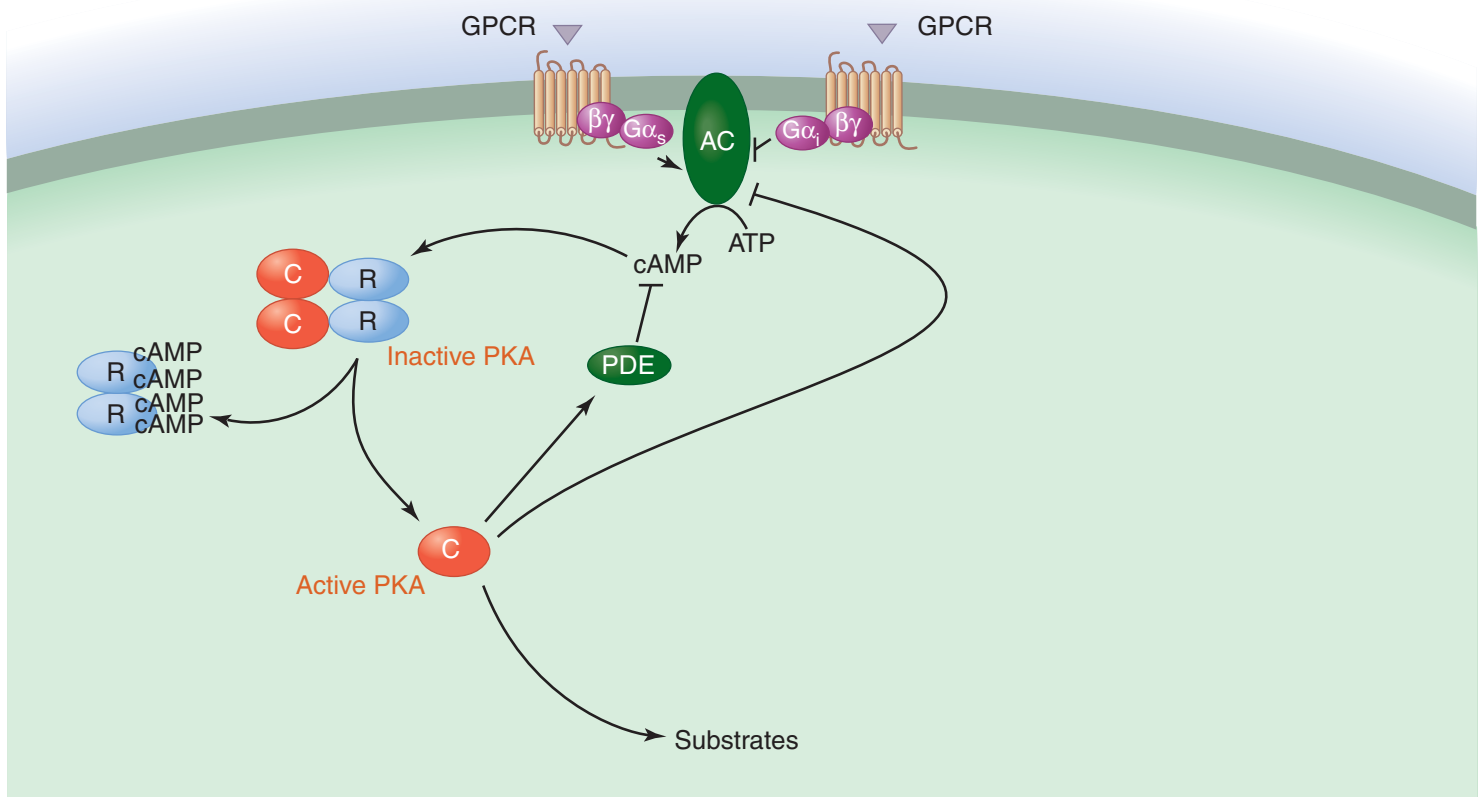

Figure 2. (A) cAMP is the archetypical second messenger. Its levels increase rapidly following receptor-mediated activation of adenylyl cyclase (AC), which catalyzes the conversion of adenosine monophosphate (AMP) to cAMP. This small second messenger activates PKA at specific cellular locations as a result of anchoring of PKA to A-kinase-anchoring proteins (AKAPs). In addition, cAMP activates EPACs. (B) AC activity is controlled by the opposing actions of the $G_{s}$ and $G_{i}$ proteins. The cAMP produced by AC activates PKA by binding to its $R$ subunit. This releases the $\mathrm{C}$ subunit. The signal can be terminated by the action of phosphodiesterase (PDE) enzymes. 


\subsection{3'-5'-Cyclic Guanosine Monophosphate and cGMP-Dependent Protein Kinase}

$3^{\prime}-5^{\prime}$-cyclic guanosine monophosphate (cGMP) is another cyclic nucleotide that serves as a second messenger. cGMP is often synthesized by receptor guanylyl cyclases, which have their catalytic domains close to the inner face of the plasma membrane and are stimulated by small peptide factors that bind to their extracellular domains. It can also be produced by soluble cytoplasmic guanylyl cyclases, which are stimulated by nitric oxide. This latter signaling pathway is involved in a number of important physiological processes, including smooth muscle relaxation and neurotransmission (see Heldin et al. 2014). cGMP targets cGMPdependent protein kinase (PKG), a dimeric enzyme that has an $\mathrm{R}$ and $\mathrm{C}$ domain within the same polypeptide chain. When cGMP levels are low, PKG is dormant; however, when cGMP levels are elevated, two molecules bind to each $\mathrm{R}$ domain in the dimer, exposing the active catalytic domains. There are two PKG isozymes: the type I enzyme is soluble and predominantly cytoplasmic, whereas the type II enzyme is particulate and is attached to a variety of biological membranes. PKG phosphorylates peptide sites with the general consensus-RRXS/TX. Hence, PKA and PKG have overlapping substrate specificities. However, a major difference is that PKG expression is restricted to the brain, lungs, and vascular tissue, where this enzyme controls important physiological processes, including the regulation of smooth muscle relaxation, platelet function in the blood, cell division, and aspects of nucleic acid synthesis. PKG causes relaxation of vascular smooth-muscle cells, for example, by phosphorylating several structural proteins that are vital for this process.

\subsection{Other cAMP and cGMP Targets}

Other cAMP and cGMP targets also play key roles in cellular physiology. For example, cyclic nucleotide-gated channels (nonselective channels that allow many ions to flow into or out of a cell) have important functions in retinal photoreceptors and olfactory receptor neurons (see Julius and Nathans 2012). Most notably, cGMP is a key second messenger in vision: photoisomerization of the chromophore in the light receptor, rhodopsin, produces a conformational change in the receptor that allows it to activate the $G$ protein transducin, which, in turn, activates a cGMP $\mathrm{PDE}$. The resulting reduction in the concentration of cGMP leads to the closure of sodium and calcium channels and, thus, hyperpolarization of photoreceptor cells, leading to changes in neurotransmitter release. Mutations in many components of this pathway, including the PDE, cause blindness. Regulation of ion channels by cAMP is particularly important in the sinoatrial node of the heart, in which
cAMP-responsive hyperpolarization-activated cyclic nucleotide-gated (HCNs) channels help to generate pacemaker currents that control cardiac contractility (see Kuo and Ehrlich 2014). Other classes of HCN channel have analogous functions in the brain and nervous system. cAMP also controls the cAMP-responsive guanine nucleotide exchange factor EPAC1, a protein that promotes activation of the Rap1 GTPase to regulate cell adhesion by stimulating integrin molecules in the plasma membrane (Bos 2003).

\subsection{Cyclic Nucleotide PDEs}

Termination of cAMP and cGMP signals is mediated by PDEs. These enzymes represent a vast gene family of 11 distinct subtypes and more than 100 isoforms that can break the phosphoester bond of either cyclic nucleotide to liberate AMP or GMP (Beavo and Brunton 2002). PDE activity can be regulated in a variety of ways. For example, calcium-dependent processes control the activity of the PDE1 and PDE2 isoforms, PKA phosphorylation attenuates the activity of PDE3 and PDE4 isoforms, and PKA or PKG phosphorylation participates in the control of PDE5. Less is known about the mechanisms of regulation for PDE6-11. More recently, there has been considerable interest in the development and clinical application of smallmolecule PDE inhibitors. Selective PDE inhibitors that produce elevated levels of cAMP/cGMP have been used clinically to alleviate chronic obstructive pulmonary disease, asthma, and combat certain immune disorders, but their most celebrated therapeutic application has been in the treatment of male erectile dysfunction. Sildenafil citrate (Viagra) and its relatives act by inhibiting cGMPspecific PDE5 (Beavo and Brunton 2002) in the arterial wall smooth muscle of the penis, which elevates cGMP and increases blood flow.

\section{LIPID AND LIPID-DERIVED SECOND MESSENGERS}

Two seemingly unrelated discoveries half a century ago provided the first insights into how cells use lipids to signal. Hokin and Hokin discovered that cholinergic stimulation of pancreatic slices promotes incorporation of ${ }^{32} \mathrm{P}$ from radiolabeled ATP into phospholipids, which led to an explosion of studies showing that numerous extracellular signals promote hydrolysis of phosphoinositides in cells and eventually the identification of DAG as a major second messenger. During this period, Yasutomi Nishizuka purified the enzyme PKC and showed it is the target for this lipid second messenger (Nishizuka 1992).

We now know that many extracellular signals trigger hydrolysis of two classes of lipids to generate second mes- 
A.C. Newton et al.

A
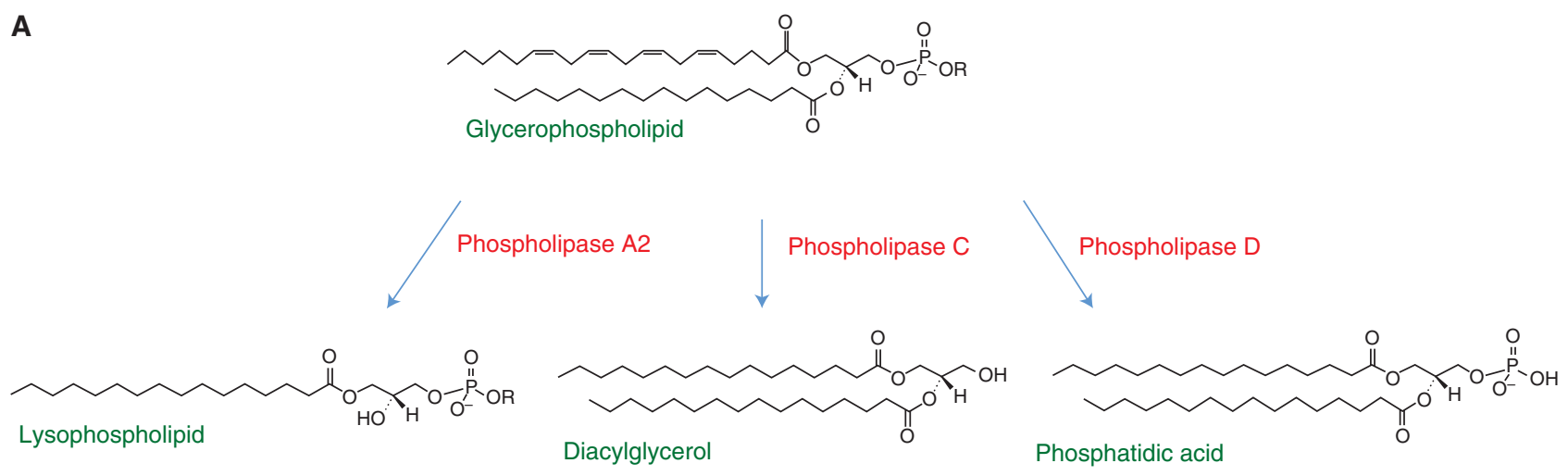

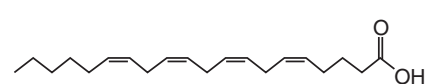

Arachidonic acid

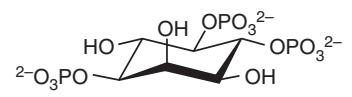

Inositol 1,4,5-trisphosphate

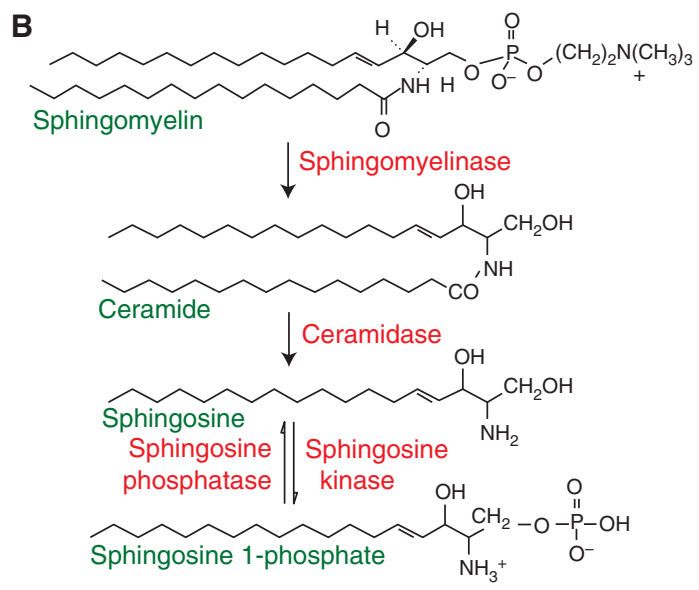

Figure 3. Lipid-derived second messengers. (A) Hydrolysis of glycerophospholipids results in the production of lysophospholipids, free fatty acids (arachidonic acid is shown), diacylglycerol, phosphatidic acid, and, in the case of hydrolysis of $\mathrm{PIP}_{2}$, the water soluble inositol 3,4,5-trisphosphate. (B) Hydrolysis of sphingolipids yields ceramide, sphingosine, and sphingosine 1-phosphate.

sengers: glycerolipids, whose hydrophobic backbone is DAG (e.g., phosphatidylinositol 4,5-bisphosphate, $\mathrm{PIP}_{2}$ ), and sphingolipids, whose hydrophobic backbone is ceramide (e.g., sphingomyelin). Both produce a variety of products that are involved in cell signaling (Fig. 3). Binding of ligands to receptors that couple to lipid-modifying enzymes (see below) results in activation of enzymes that hydrolyze specific acyl chains or polar head groups from each lipid class to generate lipid second messengers. Specifically, hydrolysis of acyl chains generates lysophospholipids (e.g., lysophosphatidylcholine and lysophosphatidic acid through hydrolysis catalyzed by phospholipase A2) and lysophingolipids (e.g., sphingosine through hydrolysis catalyzed by ceramidases). It also produces free fatty acids, such as arachidonic acid, which are important signaling entities in their own right.
Hydrolysis of polar head groups from glycerophospholipids by phospholipase D and PLC results in generation of phosphatidic acid and DAG, respectively. The polar head group released following $\mathrm{PIP}_{2}$ hydrolysis, $\mathrm{IP}_{3}$, is a key second messenger itself. $\mathrm{IP}_{3}$ can also be further phosphorylated to form polyphosphoinositols that serve as additional second messengers. Hydrolysis of the polar head group from sphingomyelin, catalyzed by sphingomyelinase, produces ceramide. Further hydrolysis of the acyl chain by ceramidase produces sphingosine, and the subsequent phosphorylation of this by sphingosine kinase produces sphingosine 1-phosphate.

Lipid second messengers that retain two acyl chains (e.g., phosphatidic acid, DAG, and ceramide) remain membrane associated, but the decreased lipophilicity of second messengers that retain only one acyl chain (lysolipids such 
as lysophosphatidic acid and sphingosine) allows them to dissociate from membranes and serve as soluble second messengers. Finally, note that in addition to its hydrolysis, $\mathrm{PIP}_{2}$ can be phosphorylated to produce another key second messenger, $\mathrm{PIP}_{3}$ (see below).

\section{1 $\mathrm{IP}_{3}$ and DAG}

Signals from both GPCRs (e.g., histamine receptors) and RTKs (e.g., epidermal growth factor [EGF] receptors) can result in activation of PLC, which cleaves phospholipids to generate DAG and $\mathrm{IP}_{3}$. In the case of GPCR signaling, lipid hydrolysis is mediated by binding of $\mathrm{G}$ proteins (notably $\mathrm{Gq}$ ) to phospholipases (PLC $\beta$ ); in the case of RTKs, lipid hydrolysis is mediated by recruitment of phospholipases (PLC $\gamma$ ) to tyrosine-phosphorylated proteins at the plasma membrane (tyrosine phosphorylation of PLC $\gamma$ by RTKs also stimulates its activity directly). If the lipid cleaved is $\mathrm{PIP}_{2}$ (rather than phosphatidylcholine [PC]), then watersoluble $\mathrm{IP}_{3}$ is also produced. $\mathrm{IP}_{3}$ binds to $\mathrm{IP}_{3}$ receptors on the endoplasmic reticulum (ER), and other organelles, causing release of calcium into the cytosol (Fig. 1). It can be further modified to yield additionally phosphorylated phosphoinositols, including diphosphoryl inositol phosphates (Tsui and York 2010). Inositol 1,3,4,5-tetrakisphosphate $\left(\mathrm{IP}_{4}\right)$ activates chloride channels. Inositol 1,2,3,4,5,6hexaphosphate $\left(\mathrm{IP}_{6}\right)$ is a compound found in plants (hence, its name phytic acid), but it is also present in yeast and animal cells, along with the enzymes that synthesize and metabolize it, and is gaining interest as a potential anticancer agent because of its apoptosis-promoting properties. The DAG sensor is a small globular domain, called the $\mathrm{C} 1$ domain, originally identified in PKC. Approximately 30 other proteins contain a $\mathrm{C} 1$ domain (Colon-Gonzalez and Kazanietz 2006), including protein kinase D, Ras, gastrin-releasing polypeptides, DAG kinase, and $n$-chimaerin.

PKC represents a family of nine genes grouped into three families (Newton 2009). The so-called conventional PKC isozymes require the coordinated presence of both calcium (sensed by the C2 domain) and DAG (sensed by the adjacent $\mathrm{C} 1$ domain) for activation and thus transduce signals that trigger $\mathrm{PIP}_{2}$ hydrolysis, but not those that trigger hydrolysis of other phospholipids, such as PC (because these do not mobilize calcium via $\mathrm{IP}_{3}$ ). Novel isozymes of PKC do not have a calcium sensor, but because they bind DAG with an affinity two orders of magnitude higher than conventional PKC isozymes, they are efficiently activated by DAG alone. Thus, they can transduce signals triggered by PC hydrolysis. A third class of PKC isozymes, the atypical PKCs, do not respond to DAG or calcium. Signaling by conventional and novel PKC isozymes is terminated by phosphorylation of DAG by DAG kinase, which removes the second messenger. Note that PKC isozymes are constitutively phosphorylated but, unlike many other kinases, these phosphorylations do not acutely regulate activity.

DAG- or calcium-dependent translocation of conventional and novel PKC isozymes to the membrane is a hallmark of their activation (see Fig. 4). In unstimulated cells, PKC localizes to the cytosol, where it may be concentrated on specific protein scaffolds. For example, the conventional PKC $\alpha$ binds to the PDZ-domain scaffold DLG1. PIP 2 hydrolysis provides calcium, which binds to the $\mathrm{C} 2$ domain and thus recruits cytosolic PKC to the plasma membrane; there, PKC binds to the membrane-embedded second messenger DAG via its $\mathrm{C} 1$ domain. Binding of both the $\mathrm{C} 2$ and $\mathrm{C} 1$ domains to membranes provides the energy to release an autoinhibitory pseudosubstrate segment from the substrate-binding cavity, allowing PKC to phosphorylate substrates and relay signals. Interestingly, a function common to many of the PKC isozymes is that their phosphorylation of certain substrates terminates signaling pathways. For example, phosphorylation of receptors such as the EGF and insulin receptors by PKC promotes their internalization and degradation, thus acting as a negative feedback loop to attenuate signaling via these pathways.

PKC has a unique signature of activation depending on its cellular location (Gallegos and Newton 2008). In general, its activation kinetics mirror those for the increase in intracellular calcium concentration, and deactivation kinetics mirror the decay of DAG. Thus, membranes such as the Golgi in which DAG production is sustained serve as a platform for sustained PKC activity, whereas membranes such as the plasma membrane where DAG is more rapidly removed by phosphorylation serve as platforms for transient PKC activity. Although PKC can phosphorylate cytosolic targets, these events likely occur at the membrane. Reduction in cytoplasmic calcium levels and phosphorylation of DAG by DAG kinase effectively terminates PKC signaling.

\section{2 $\mathrm{PIP}_{3}$ and Akt Signaling}

Binding of growth factors to receptor tyrosine kinases results in the activation of PI3K isoforms (Fig. 4B), which catalyze the phosphorylation of $\mathrm{PIP}_{2}$ at the $3^{\prime}$ position to generate the very minor, but highly efficacious, lipid second messenger $\mathrm{PIP}_{3}$ in the plasma membrane (Cantley 2002). PI3K also phosphorylates phosphatidylinositol and phosphatidylinositol 4-phosphate (PIP) at the $3^{\prime}$ position to generate corresponding $3^{\prime}$-phosphoinositides that also serve as second messengers. PIP $_{2}$ is itself a minor component of the plasma membrane, accounting for $\sim 0.05 \%$ of the total phospholipid, yet the phosphorylation of $10 \%$ of this pool effectively transduces growth factor signals. 
A.C. Newton et al.

\section{A}

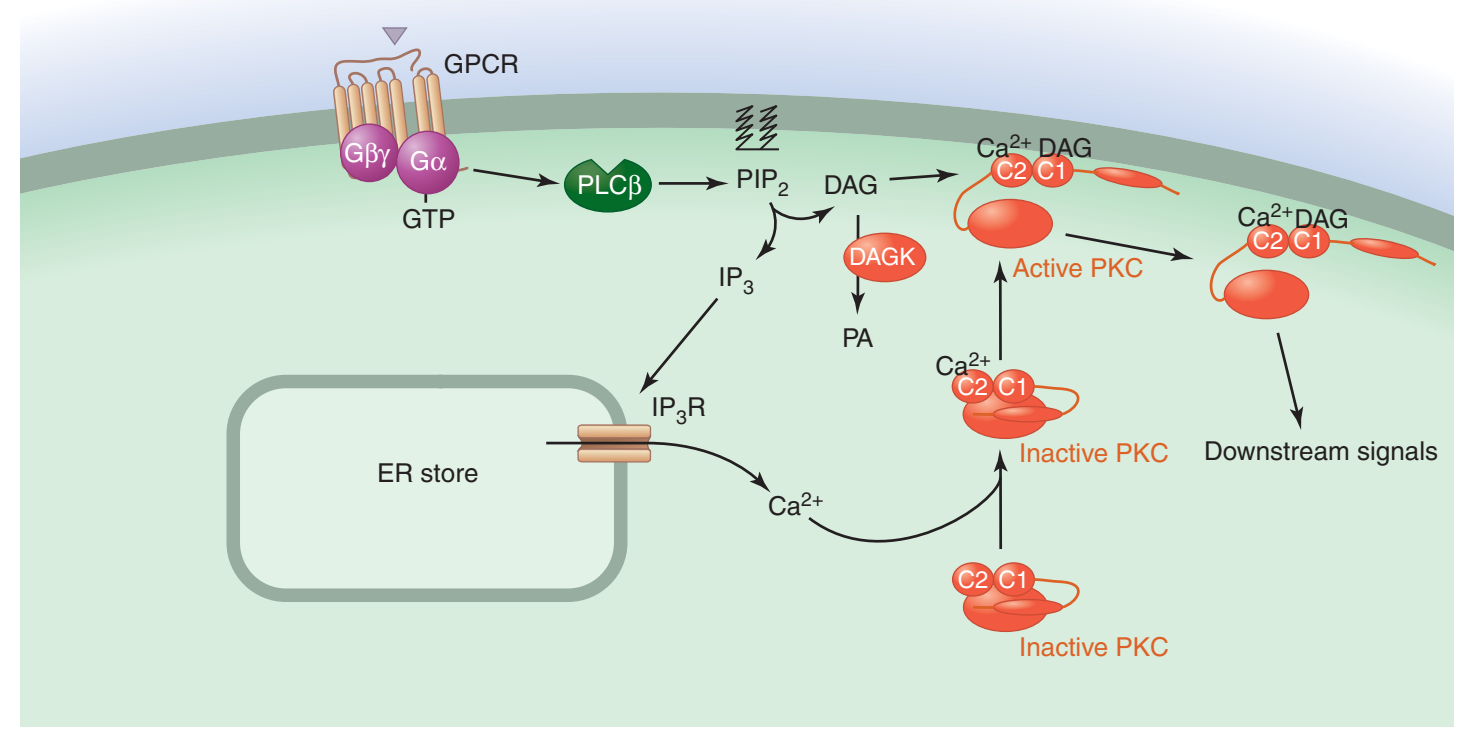

B

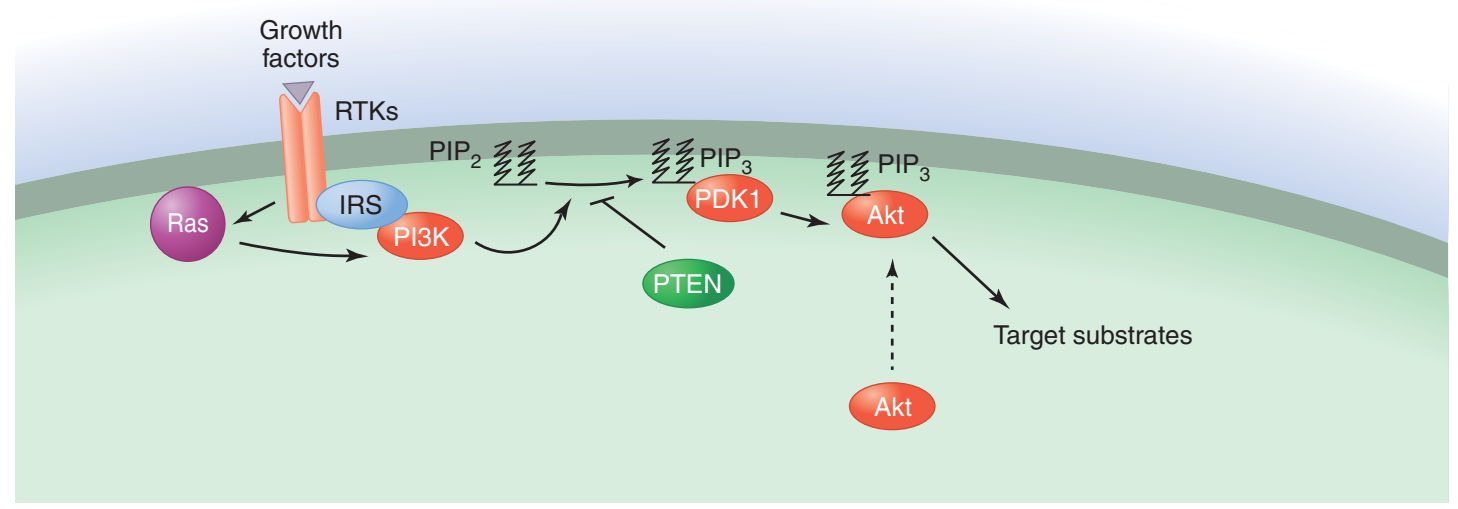

Figure 4. (A) PKC transduces signals that promote phospholipid hydrolysis. Signals that cause phospholipase-Cmediated hydrolysis of $\mathrm{PIP}_{2}$ activate conventional PKC isozymes by a two-step mechanism. First, calcium (whose levels increase following $\mathrm{IP}_{3}$ production) binds to the $\mathrm{C} 2$ domain of $\mathrm{PKC}$. This increases the affinity of the module for the plasma membrane, causing PKC to translocate to the membrane. Here, it binds its allosteric activator, DAG. This binding produces a conformational change that expels the autoinhibitory pseudosubstrate segment from the active site, allowing substrate phosphorylation and downstream signaling. (B) Activation of PI3K following engagement of growth factor receptors such as insulin receptor generates the phospholipid $\mathrm{PIP}_{3}$, which recruits the kinases PDK1 and Akt to the membrane. Subsequent phosphorylation events lead to activation of Akt.

The reason for this highly effective signaling is the use of protein modules that bind with high affinity and specificity to the various phosphorylated species of the inositol head group (e.g., inositol 3,4,5-trisphosphate versus inositol 3,4-bisphosphate) that is exposed to the cytosol. These include pleckstrin homology (PH), FYVE, and PB domains (Lemmon 2007; Hemmings and Restuccia 2012).

The best defined target for $\mathrm{PIP}_{3}$ is the prosurvival kinase Akt (Manning and Cantley 2007). Like PKC, Akt is present in the cytosol in unstimulated cells. $\mathrm{PIP}_{3}$ produced following PI3K activation recruits Akt to the plasma membrane via its $\mathrm{PH}$ domain. This triggers the phosphorylation of Akt at two sites, leading to its activation and downstream signaling. The first phosphorylation is catalyzed by the phosphoinositide kinase PDK1 (also recruited to the membrane by $\mathrm{PIP}_{3}$ ) at a segment near the entrance to the active site, which, in turn, leads to rapid phosphorylation at a carboxy-terminal site. Autophosphorylation 
and the mTORC2 kinase complex have been proposed to regulate this second site (see Laplante and Sabatini 2012). Once phosphorylated, Akt is locked in an active and signaling-competent conformation and can be released from the plasma membrane to signal throughout the cell, including the nucleus. Signaling is terminated by dephosphorylation of $\mathrm{PIP}_{3}$ and dephosphorylation of Akt. The former is catalyzed by the tumor suppressor PTEN, a lipid phosphatase, which removes the lipid second messenger by dephosphorylating the $3^{\prime}$ phosphate of $\mathrm{PIP}_{3}$. Dephosphorylation of the two Akt sites is catalyzed by protein phosphatases such as the tumor suppressor PHLPP.

\subsection{Sphingolipid Hydrolysis and Protein Targets that Control Apoptosis}

Sphingolipids are a class of bioactive lipids that play important roles in diverse cellular responses (Hannun and Obeid 2008). The major signaling lipids derived from sphingomyelin are ceramide, sphingosine, and sphingosine 1-phosphate, which are produced by the action of sphingomyelinase, ceramidase, and sphingosine kinase, respectively (Fig. 3).

Ceramide propagates information in stress-response pathways; it is produced following activation of receptors by stimuli such as cytokines or death ligands and also by nonreceptor signals in response to radiation, cytotoxic insult, or infection by pathogens. Sphingosine also has apoptotic roles, although its direct targets in cells are unclear. In contrast to ceramide and sphingosine, sphingosine 1phosphate promotes prosurvival signaling. When secreted, it binds to a class of GPCRs that promote diverse cellular effects, including cell-survival, differentiation, inflammation, and angiogenesis (Pitson 2011). Intracellular sphingosine 1-phosphate acts as a second messenger, activating enzymes such as the TRAF2 E3 ligase and some histone deacetylases.

\subsection{Lysolipids, Prostaglandins, and Other Eicosanoids}

Oxidation of 20-carbon fatty acids produces eicosanoids, thus signaling molecules that bind to GPCRs to mediate inflammatory and immune responses (Wymann and Schneiter 2008). Phospholipase-A2-mediated hydrolysis of phospholipids containing arachidonic acid (a 20-carbon unsaturated fatty acid) in the $s n-2$ position of the glycerol backbone (see Fig. 3) yields a fatty-acid product that can be oxidized by cyclooxygenases to yield prostaglandins, or by lipooxygenases to yield leukotrienes. These signaling molecules bind to specific receptors that couple to diverse pathways. Many of these are involved in inflammatory re- sponses. Notably, leukotrienes bind to GPCRs that cause inflammatory responses common in asthma, and, as such, leukotriene pathways serve as targets for antiasthma drugs. Aspirin inhibits cyclooxygenases and thus the production of prostaglandins, which are inflammatory (Venteclef et al. 2011). As mentioned above, arachidonic acid itself also serves as a second messenger.

\section{IONS AS INTRACELLULAR MESSENGERS}

Ions such as sodium, potassium, calcium, magnesium, protons, chloride, iron, and copper play essential roles in cell function. Many ions act as cofactors for structural proteins and enzymes. Moreover, cellular processes are sensitive to changes in their ambient ionic environment; changes in $\mathrm{pH}$, for example, can alter enzymatic activity and the behavior of cellular ion transporters (VaughanJones et al. 2009). In addition, ions control cellular activity by spreading electrical signals, for example, action potentials in heart and neurons.

Ions such as calcium and magnesium can also play direct roles as dynamic intracellular messengers that regulate specific protein targets during signal transduction (Fig. $5 \mathrm{~A})$. These ions are imported from the extracellular milieu or mobilized from intracellular stores and control the activity of protein targets by binding to specific motifs on the protein itself or upstream regulators (e.g., calmodulin) (Berridge et al. 2000). Note that most ions should not be considered intracellular messengers, however. For example, the sodium ions that enter cardiac myocytes during an action potential serve only to depolarize the cell membrane. This causes the opening of voltage-operated calcium channels (VOCCs), allowing influx of the real messengercalcium ions-which control contraction by binding to proteins such as calmodulin and troponin C (Kuo and Ehrlich 2014). Similarly, to reverse an action potential, potassium ions are rapidly extruded and the membrane potential is restored, but it is the reversion of the calcium concentration to the prestimulated state through the action of the sodium/calcium exchanger (NCX) that represents signal termination (sodium and potassium levels are returned to the original state by the sodium/potassium ATPase $\left[\mathrm{Na}^{+} / \mathrm{K}^{+}\right.$-ATPase $]$, so that another action potential can be evoked).

A key reason for using ions as messengers is speed of response. Cells use energy to maintain gradients of ions across their lipid membranes. By activating channels or transporters, cells can use the potential energy established by the electrochemical gradient of an ion to rapidly generate a cellular signal (Clapham 2007). Unlike other intracellular messengers, ionic signals can be generated with no enzymatic steps. The speed of the response depends on the 
A

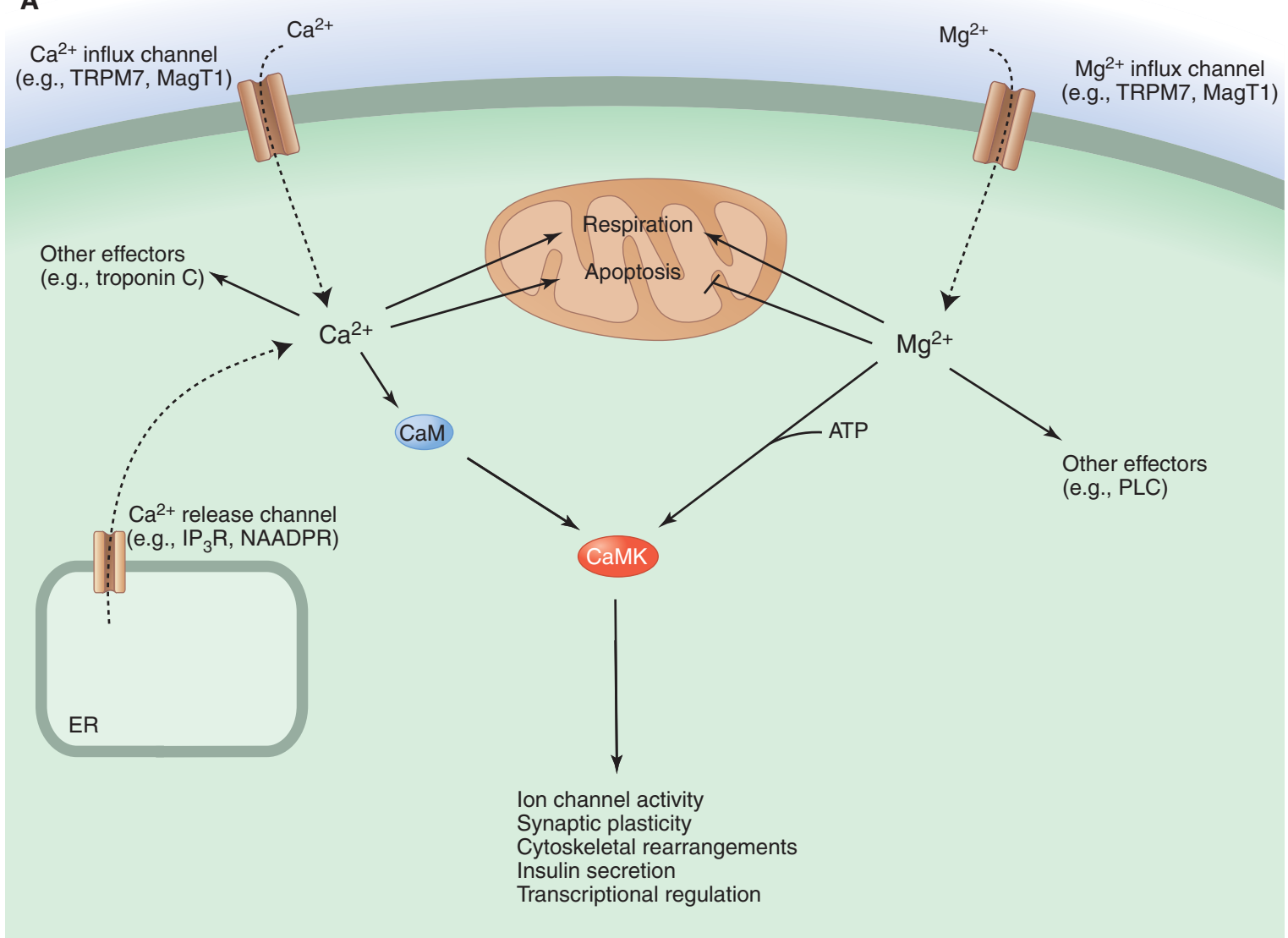

B $\quad \mathrm{IP}_{3} \mathrm{R}$

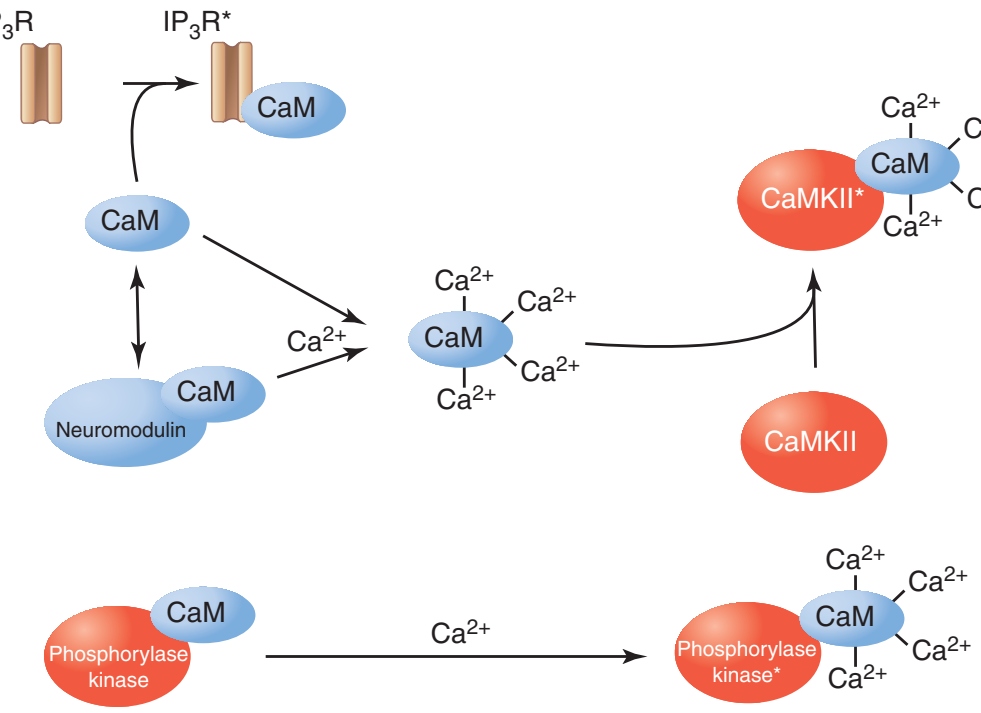

Figure 5. (A) Calcium and magnesium signals. Both ions can enter cells via channels in the plasma membrane. In addition, calcium is stored in organelles such as the ER. Calcium exerts its effects by binding to numerous cellular protein targets, including calmodulin, whereas magnesium may function as a calcium mimetic or have magnesiumspecific effects. (B) The various ways in which calmodulin can function to alter cellular targets. It is generally thought that cellular calmodulin is largely bound to proteins even when the calcium concentration is low, and that there is a relatively small pool of cytosolic calcium-free calmodulin (apocalmodulin). However, even apocalmodulin can regulate specific cellular processes (e.g., $\mathrm{IP}_{3}$ receptors, $\mathrm{IP}_{3} \mathrm{Rs}$ ). When the calcium concentration is elevated, calcium ions bind to calmodulin. This causes calmodulin to be displaced from some targets and associate with others. In some cases (e.g., phosphorylase kinase), calmodulin is a constitutively bound subunit that binds calcium and activates the enzyme when the calcium concentration is elevated. Other calcium-binding proteins, such as neuronal calcium sensors, may also display complex interactions with their various targets. ${ }^{*}$ CaM-dependent inhibition of IP3R channels. 
rate at which the intracellular concentration of the ion changes and the proximity of the ions to their cellular targets. For example, action potentials cause the fast release of neurotransmitters at nerve terminals because the cytosolic concentration of calcium ions just beneath the plasma membrane increases from $\sim 100 \mathrm{nM}$ to $>10 \mu \mathrm{M}$ within milliseconds (Berridge 2006). In situations in which ions have to diffuse further before encountering their target(s), the response will be slower. As we discuss below, the ability to generate different spatiotemporal patterns, such as waves and oscillations, is another important advantage of ionic intracellular messengers.

\subsection{Calcium}

Calcium is an extremely versatile intracellular messenger that controls a wide range of cellular functions by regulating the activity of a vast number of target proteins. The cellular effects of calcium are mediated either by direct binding to a target protein, or stimulation of calcium sensors that detect changes in calcium concentration and then activate different downstream responses (Berridge 2004). The multitude of sensors that mediate effects of calcium can be characterized by the nature of their calcium-binding site(s). The most common calcium-binding motifs are EF-hands and C2 domains. Synaptotagmin and troponin $\mathrm{C}$ are examples of proteins with $\mathrm{C} 2$ domains and EF-hands, respectively. Calcium sensors also act by recruiting a range of intermediary effectors, such as calcium-sensitive enzymes-for example, calcium/calmodulin-dependent protein kinases (CaMKs), calcineurin (also known as protein phosphatase $2 \mathrm{~B}$ ), myosin light chain kinase, and phosphorylase kinase (see Kuo and Ehrlich 2014).

\subsection{Control of Calcium Levels}

Intracellular calcium levels are controlled by an assortment of channels, pumps, transporters, buffers, and effector moieties. At rest, cytosolic calcium is maintained at $\sim 100 \mathrm{nM}$. In most cases, its levels are elevated by the opening of channels located either on various organellar stores or in the plasma membrane. Release of calcium from internal stores represents a major source of signal calcium for many cells. The principal calcium stores are the ER, sarcoplasmic reticulum (SR), Golgi, and acidic organelles of the endolysosomal system (Bootman et al. 2002). Calcium release channels are present on the membranes of these organelles and gate the flux of calcium from the ER/SR lumen into the cytosol. Ubiquitous calcium-release channels include the $\mathrm{IP}_{3} \mathrm{Rs}$ that respond to $\mathrm{IP}_{3}$ produced by hydrolysis of $\mathrm{PIP}_{2}$ (Parys and De Smedt 2012), ryanodine receptors (Belevych et al. 2013), and two-pore channels that respond to nicotinic acid adenine dinucleotide phosphate (Galione 2011).

Channels that permit the influx of calcium across the plasma membrane are typically characterized by their activation mechanism. Receptor-operated calcium channels and second messenger-operated calcium channels are opened by the binding of an external or internal ligand. Examples of these are $N$-methyl-D-aspartate (NMDA) receptors that respond to the neurotransmitter glutamate (see Kennedy 2013), and Orai channels regulated by the intracellular messenger arachidonic acid. VOCCs that are activated by a change in membrane potential are widely expressed in excitable tissues and can be divided into three families $\left[\mathrm{Ca}_{\mathrm{V}} 1\right.$ (L-type), $\mathrm{Ca}_{\mathrm{V}} 2(\mathrm{~N}, \mathrm{P} / \mathrm{Q}$, and $\mathrm{R}$ type), and $\mathrm{Ca}_{\mathrm{V}} 3$ ( $\mathrm{T}$ type)], which have specific characteristics and functions (Catterall 2011). The transient receptor potential (TRP) family includes a number of calcium-permeable channels with distinct activation mechanisms (Gees et al. 2012). Depletion of ER or SR calcium activates "store-operated" calcium entry. This pathway for calcium influx has been known for more than two decades, and the store-operated current ( $\mathrm{I}_{\text {crac }}$, for calcium-release-activated current) has been well characterized. However, the molecular players, STIM (stromal interaction molecule) and Orai, have only been identified relatively recently through investigation of patients with severe combined immunodeficiency caused by a lack of calcium influx into their T lymphocytes (Hogan et al. 2010).

\subsection{Calcium Buffers}

Cells express a number of calcium-binding proteins that buffer calcium changes within various cellular compartments and modulate calcium signals. The rapid binding of calcium by the cytosolic buffers parvalbumin and calbindin D-28k shapes both the spatial and temporal properties of intracellular calcium signals (Schwaller 2010). ER/ SR calcium-binding proteins (e.g., calsequestrin, calreticulin, GRP78, and GRP94) facilitate the accumulation of large amounts of calcium, which is necessary for rapid cell signaling (Prins and Michalak 2011). Mitochondria also play a key buffering role in that they express a calcium uniporter capable of taking up substantial amounts of calcium whenever the cytosolic calcium concentration increases during signaling (Rizzuto and Pozzan 2006). The uptake of calcium into the mitochondrial matrix stimulates the citric acid cycle to produce more ATP. This increased oxidation also enhances mitochondrial reactive oxygen species (ROS) formation, which contributes to redox signaling pathways. Loading of calcium into mitochondria is believed to be essential to avoid induction of autophagy. 
However, exaggerated mitochondrial calcium loading can precipitate apoptosis (Baumgartner et al. 2009).

\subsection{Signal Termination}

Calcium pumps and exchangers are responsible for pumping calcium out of the cell or back into the ER/SR to terminate a calcium signal. These pumps and exchangers operate at different times during the recovery process. NCX proteins have low affinities for calcium, but have high capacities that enable them to rapidly remove large quantities of calcium and are especially evident in excitable cells (Nicoll et al. 2013). The plasma membrane calcium-ATPase and SR/ER calcium-ATPase enzymes have lower transport rates but higher affinities, which means that they operate at relatively low cytosolic calcium concentrations (Vandecaetsbeek et al. 2011). Calcium/hydrogen exchangers are important for the loading of calcium into endo/lysosomal compartments.

\subsection{Spatiotemporal Organization of the Calcium Signaling Machinery}

The substantial diversity of cellular calcium signals in different cell types reflects their use of distinct combinations and arrangements of calcium-transport mechanisms. In neurons, for example, microscopic calcium signals trigger the release of neurotransmitter-containing vesicles at presynaptic terminals (Berridge 2014). The calcium signal is a plume of ions around the mouth of an open channel that dissipates within milliseconds and can only activate processes within a few tens of nanometers. The receiver for the calcium signal is synaptotagmin, a calcium-binding protein that promotes fusion of the neurotransmittercontaining vesicle with the neuronal plasma membrane. The rapidity of this response depends on the calcium channels and exocytotic machinery (SNARE complexes) being linked together within a highly localized microdomain. A key component of the SNARE complex is SNAP-25, a membrane-bound protein that interacts with both the VOCCs and synaptotagmin. In contrast, the regular beating of the heart relies on the sequential elevation of calcium levels within all the myocytes of the atrial and ventricular chambers. In this case, the calcium signal is global, occurring across the whole volume of each myocyte to evenly activate troponin $\mathrm{C}$, thereby allowing actin and myosin to engage and cause contraction (Kuo and Ehrlich 2014).

An important driver for global calcium signaling is regenerative calcium elevation-that is, the autocatalytic increase in cellular calcium concentration. Regenerative calcium signals arise because several components of the calcium signaling toolkit, such as PLC, RYRs, and $\mathrm{IP}_{3} \mathrm{Rs}$, are activated by calcium (Roderick et al. 2003). The opening of one calcium channel can therefore promote a positive feed-forward reaction in which more calcium ions enter the cytosol. This regenerative calcium-induced calcium release (CICR) process can override cellular calcium buffers, enabling rapid coordinated surges in calcium concentration. The triggering of CICR is typically the critical event in causing the transition from local to global calcium signaling. Without CICR, the global calcium signals in cardiac myocytes that trigger contraction (described above) would not occur. CICR leads to a rapid increase in calcium concentration. Within an individual cell, each spike of calcium caused by CICR is evident as calcium waves, such as the calcium waves evoked by fertilization of an oocyte (see Wakai et al. 2011). Microscopic analysis and modeling has shown that such waves propagate in a salutatory manner, involving successive rounds of CICR and diffusion, as the wave jumps from a cluster of calcium channels to the next (Thul et al. 2012). Such waves can engulf the entirety of the cellular cytoplasm, and pervade into the nucleus to activate or inhibit transcription (Bootman et al. 2009).

If a cellular stimulus is not sufficient to trigger a global response, then only local calcium elevations will occur. The calcium ions emanating from channels during local calcium signaling only switch on processes within their immediate vicinity. The sphere of action of such microdomains depends on how long the channels are open, their ability to conduct calcium, and the capacity of surrounding calcium buffers and homeostatic mechanisms that remove calcium (Parekh 2008). Calcium buffers and pumps are highly effective at restricting the diffusion of calcium so that the calcium concentration declines exponentially with distance from a calcium source. If local calcium events do not turn into global calcium signals, the proximity of particular effectors and their affinity for calcium determines the response. For example, relatively low-affinity effector molecules such as synaptotagmin (described above) and BK potassium channels (big calcium-activated potassium channels, also called maxi-K channels) depend on submicrometer proximity to a channel to sense an activating calcium concentration. Sensor proteins with relatively higher affinity, such as calmodulin and SK potassium channels ( small calcium-activated potassium channels), can be activated at greater distances.

\subsection{Magnesium}

Magnesium can also be considered an intracellular messenger because its concentration can change dynamically in response to cellular stimulation ( $\mathrm{Li}$ et al. 2011). Given that magnesium binds to nucleotides, oligonucleotides, and hundreds of enzymes, it is reasonable to conclude that it is an intracellular messenger in its own right. Of its poten- 
tial binding sites, ATP is particularly important. Cellular processes typically use ATP complexed with magnesium as an energy source. Moreover, magnesium has been shown to cause prolonged inhibition of potassium channels in neurons following muscarinic acetylcholine receptor activation (an effect that is not mimicked by calcium), thereby regulating neuronal excitability (Chuang et al. 1997).

In addition, magnesium deserves consideration because it influences the effects of calcium. Indeed, magnesium and calcium are typically thought to have antagonistic actions. Magnesium frequently inhibits the transport and cellular activities of calcium and can prevent pathological consequences of increases in calcium levels (Romani 2013). Like calcium, there is an electrochemical gradient of magnesium across the plasma membrane that can serve as a reservoir for signal generation. The extracellular concentrations of magnesium and calcium are similar (1.1$1.5 \mathrm{mM}$ ), and magnesium can also act as a "calcimimetic" (e.g., by binding to the calcium-sensing receptor), a GPCR that has pleiotropic actions. Within cells, the magnesium concentration $(0.3-1.5 \mathrm{mM})$ is several orders of magnitude higher than that of calcium. It has been suggested that mitochondria might serve as a store of magnesium and that magnesium can potentially regulate cellular respiration (Wolf and Trapani 2012). Moreover, magnesium in the mitochondrial matrix inhibits permeability transition pore (PTP) activation, an increase in the leakiness of the inner mitochondrial membrane that allows solutes $<1500 \mathrm{Da}$ to pass, and can precipitate mitochondrial swelling, apoptosis, and cell death. Calcium promotes PTP, so magnesium acts as a counteracting antagonist.

Like calcium, magnesium has a plethora of transport pathways. Of these, TRPM6 and TRPM7 (members of the TRP family) are relatively well understood. TRPM6 is restricted to kidney tubules and the intestinal epithelium, and plays an important role in magnesium (re)adsorption (defective TRPM6 function leads to hypomagnesemia), whereas TRPM7 is ubiquitously expressed in mammals. Both TRPM6 and TRPM7 are "chanzymes": ion channels that incorporate a kinase domain. Interestingly, TRPM7 is regulated by $\mathrm{PIP}_{2}$, the source of the calcium-mobilizing messenger $\mathrm{IP}_{3}$. Moreover, it binds to PLC, the enzyme that hydrolyses $\mathrm{PIP}_{2}$. Consequently, hormonal stimulation of cells will lead to both a calcium signal (via $\mathrm{IP}_{3}$ production) and a change in magnesium flux (via loss of $\mathrm{PIP}_{2^{-}}$ mediated regulation of TRPM7) (Langeslag et al. 2007). MagT1 is also believed to be a key cellular magnesium channel. Like TRPM6 and TRPM7, it is located on the plasma membrane of mammalian cells. However, whereas TRPM6 and TRPM7 allow both calcium and magnesium fluxes, it is believed that MagT1 is a specific pathway for magnesium. Individuals bearing mutations in the MAGT1 gene show high levels of Epstein-Barr virus infection and a predisposition to lymphoma (Chaigne-Delalande et al. 2013).

\section{CONCLUDING REMARKS}

Second messengers disseminate information received by cellular receptors rapidly, faithfully, and efficaciously. They are small, nonprotein organic molecules or ions that bind to specific target proteins, altering their activities in a variety of ways that allow them to respond appropriately to the information received by receptors.

A key advantage of second messengers over proteins is that, unlike proteins, second messenger levels are controlled with rapid kinetics. Thus, whereas it may take tens of minutes for the levels of a protein to increase significantly, most second messenger levels increase within microseconds (e.g., ions) to seconds (e.g., DAG), They are often produced from precursors that are abundant in cells or released from stores that contain high concentrations of the second messenger; so, their generation is not rate limiting. Thus, when the appropriate signal is received, second messengers are rapidly generated, diffuse rapidly, and alter target protein function highly efficiently.

Second messengers vary significantly in size and chemical character: from ions to hydrophilic molecules such as cyclic nucleotides to hydrophobic molecules such as diacylglycerol. Moreover, the continuing discovery of new second messengers is expanding the repertoire of molecules known to convey information within the cell. Indeed, only very recently, cyclic guanosine monophosphate-adenosine monophosphate was shown to be a second messenger that is synthesized by the enzyme cGAS in response to HIV infection and binds to and activates a protein called STING, leading to induction of interferon (Wu et al. 2013). The ability to respond rapidly to information thus depends on an expanding library of small molecules.

\section{REFERENCES}

* Reference is also in this collection.

Baumgartner HK, Gerasimenko JV, Thorne C, Ferdek P, Pozzan T, Tepikin AV, Petersen OH, Sutton R, Watson AJ, Gerasimenko OV. 2009. Calcium elevation in mitochondria is the main $\mathrm{Ca}^{2+}$ requirement for mitochondrial permeability transition pore (mPTP) opening. J Biol Chem 284: 20796-20803.

Beavo JA, Brunton LL. 2002. Cyclic nucleotide research-Still expanding after half a century. Nat Rev Mol Cell Biol 3: 710-718.

Belevych AE, Radwanski PB, Carnes CA, Gyorke S. 2013. "Ryanopathy”: Causes and manifestations of RyR2 dysfunction in heart failure. Cardiovasc Res 98: 240-247.

Berridge MJ. 2004. Calcium signal transduction and cellular control mechanisms. Biochim Biophys Acta 1742: 3-7.

Berridge MJ. 2006. Calcium microdomains: Organization and function. Cell Calcium 40: 405-412. 


\section{A.C. Newton et al.}

Berridge MJ. 2014. Calcium regulation of neural rhythms, memory and Alzheimer's disease. J Physiol 592: 281-293.

Berridge MJ, Lipp P, Bootman MD. 2000. The versatility and universality of calcium signalling. Nat Rev Mol Cell Biol 1: 11-21.

Bootman MD, Berridge MJ, Roderick HL. 2002. Calcium signalling: More messengers, more channels, more complexity. Curr Biol 12: R563-R565.

Bootman MD, Fearnley C, Smyrnias I, MacDonald F, Roderick HL. 2009. An update on nuclear calcium signalling. J Cell Sci 122: 2337-2350.

Bos JL. 2003. Epac: A new cAMP target and new avenues in cAMP research. Nat Rev Mol Cell Biol 4: 733-738.

Cantley LC. 2002. The phosphoinositide 3-kinase pathway. Science 296: $1655-1657$.

Catterall WA. 2011. Voltage-gated calcium channels. Cold Spring Harb Perspect Biol 3: a003947.

Chaigne-Delalande B, Li FY, O'Connor GM, Lukacs MJ, Jiang P, Zheng L, Shatzer A, Biancalana M, Pittaluga S, Matthews HF, et al. 2013. $\mathrm{Mg}^{2+}$ regulates cytotoxic functions of NK and CD8 T cells in chronic EBV infection through NKG2D. Science 341: 186-191.

Chuang H, Jan YN, Jan LY. 1997. Regulation of IRK3 inward rectifier $\mathrm{K}^{+}$ channel by $\mathrm{ml}$ acetylcholine receptor and intracellular magnesium. Cell 89: 1121-1132.

Clapham DE. 2007. Calcium signaling. Cell 131: 1047-1058.

Colon-Gonzalez F, Kazanietz MG. 2006. C1 domains exposed: From diacylglycerol binding to protein-protein interactions. Biochim Biophys Acta 1761: 827-837.

Fischer EH, Krebs EG. 1955. Conversion of phosphorylase $b$ to phosphorylase $a$ in muscle extracts. J Biol Chem 216: 121-132.

Galione A. 2011. NAADP receptors. Cold Spring Harb Perspect Biol 3: a004036.

Gallegos LL, Newton AC. 2008. Spatiotemporal dynamics of lipid signaling: Protein kinase $\mathrm{C}$ as a paradigm. IUBMB Life 60: 782-789.

Gees M, Owsianik G, Nilius B, Voets T. 2012. TRP channels. Compr Physiol 2: 563-608.

Gilman AG. 1995. Nobel Lecture. G proteins and regulation of adenylyl cyclase. Biosci Rep 15: 65-97.

Hannun YA, Obeid LM. 2008. Principles of bioactive lipid signalling: Lessons from sphingolipids. Nat Rev Mol Cell Biol 9: 139-150.

* Hardie DG. 2012. Organismal carbohydrate and lipid homeostasis. Cold Spring Harb Perspect Biol 4: a006031.

* Heldin C-H, Lu B, Evans R, Gutkind JS. 2014. Signals and receptors. Cold Spring Harb Perspect Biol doi: 10.1101/cshperspect.a005900.

* Hemmings BA, Restuccia DF. 2012. PI3K-PKB/Akt pathway. Cold Spring Harb Perspect Biol 4: a011189.

Hogan PG, Lewis RS, Rao A. 2010. Molecular basis of calcium signaling in lymphocytes: STIM and ORAI. Annu Rev Immunol 28: 491-533.

* Julius D, Nathans J. 2012. Signaling by sensory receptors. Cold Spring Harb Perspect Biol 4: a005991.

Kemp BE, Benjamini E, Krebs EG. 1976. Synthetic hexapeptide substrates and inhibitors of $3^{\prime}: 5^{\prime}$-cyclic AMP-dependent protein kinase. Proc Natl Acad Sci 73: 1038-1042.

* Kennedy MB. 2013. Synaptic signaling in learning and memory. Cold Spring Harb Perspect Biol doi: 10.1101/cshperspect.a016824.

Krebs EG. 1993. Nobel Lecture. Protein phosphorylation and cellular regulation I. Biosci Rep 13: 127-142.

* Kuo IY, Ehrlich BE. 2014. Signaling in muscle contraction. Cold Spring Harb Perspect Biol doi: 10.1101/cshperspect.a006023.

Langeslag M, Clark K, Moolenaar WH, van Leeuwen FN, Jalink K. 2007. Activation of TRPM7 channels by phospholipase C-coupled receptor agonists. J Biol Chem 282: 232-239.

* Laplante M, Sabatini DM. 2012. mTOR signaling. Cold Spring Harb Perspect Biol 4: a011593.

* Lee MJ, Yaffe MB. 2014. Protein regulation in signal transduction. Cold Spring Harb Perspect Biol doi: 10.1101/cshperspect.a005918.

Lemmon MA. 2007. Pleckstrin homology (PH) domains and phosphoinositides. Biochem Soc Symp 2007: 81-93.
Li FY, Chaigne-Delalande B, Kanellopoulou C, Davis JC, Matthews HF, Douek DC, Cohen JI, Uzel G, Su HC, Lenardo MJ. 2011. Second messenger role for $\mathrm{Mg}^{2+}$ revealed by human T-cell immunodeficiency. Nature 475: 471-476.

Manning BD, Cantley LC. 2007. AKT/PKB signaling: Navigating downstream. Cell 129: 1261-1274.

Newton AC. 2009. Lipid activation of protein kinases. J Lipid Res 50: S266-S271.

Nicoll DA, Ottolia M, Goldhaber JI, Philipson KD. 2013. 20 years from NCX purification and cloning: Milestones. Adv Exp Med Biol 961: 17-23.

Nishizuka Y. 1992. Intracellular signaling by hydrolysis of phospholipids and activation of protein kinase C. Science 258: 607-614.

Parekh AB. 2008. $\mathrm{Ca}^{2+}$ microdomains near plasma membrane $\mathrm{Ca}^{2+}$ channels: Impact on cell function. J Physiol 586: 3043-3054.

Parys JB, De Smedt H. 2012. Inositol 1,4,5-trisphosphate and its receptors. Adv Exp Med Biol 740: 255-279.

Pitson SM. 2011. Regulation of sphingosine kinase and sphingolipid signaling. Trends Biochem Sci 36: 97-107.

Prins D, Michalak M. 2011. Organellar calcium buffers. Cold Spring Harb Perspect Biol 3: a004069.

Rizzuto R, Pozzan T. 2006. Microdomains of intracellular $\mathrm{Ca}^{2+}$ : Molecular determinants and functional consequences. Physiol Rev 86: 369-408.

Roderick HL, Berridge MJ, Bootman MD. 2003. Calcium-induced calcium release. Curr Biol 13: R425.

Romani AM. 2013. Magnesium homeostasis in mammalian cells. Metal Ions life Sci 12: 69-118.

* Sassone-Corsi P. 2012. The cyclic AMP pathway. Cold Spring Harb Perspect Biol 4: a011148.

Schwaller B. 2010. Cytosolic $\mathrm{Ca}^{2+}$ buffers. Cold Spring Harb Perspect Biol 2: a004051.

Scott JD, Pawson T. 2009. Cell signaling in space and time: Where proteins come together and when they're apart. Science 326: 1220-1224.

Sutherland EW. 1972. Studies on the mechanism of hormone action. Science 171: 401-408.

Taylor SS, Ilouz R, Zhang P, Kornev AP. 2012. Assembly of allosteric macromolecular switches: Lessons from PKA. Nat Rev Mol Cell Biol 13: $646-658$.

Thul R, Coombes S, Roderick HL, Bootman MD. 2012. Subcellular calcium dynamics in a whole-cell model of an atrial myocyte. Proc Natl Acad Sci 109: 2150-2155.

Tsui MM, York JD. 2010. Roles of inositol phosphates and inositol pyrophosphates in development, cell signaling and nuclear processes. Adv Enzyme Regul 50: 324-337.

Vandecaetsbeek I, Vangheluwe P, Raeymaekers L, Wuytack F, Vanoevelen J. 2011. The $\mathrm{Ca}^{2+}$ pumps of the endoplasmic reticulum and Golgi apparatus. Cold Spring Harb Perspec Biol 3: a004184.

Vaughan-Jones RD, Spitzer KW, Swietach P. 2009. Intracellular pH regulation in heart. J Mol Cell Cardiol 46: 318-331.

Venteclef N, Jakobsson T, Steffensen KR, Treuter E. 2011. Metabolic nuclear receptor signaling and the inflammatory acute phase response. Trends Endocrinol Metab 22: 333-343.

Wakai T, Vanderheyden V, Fissor RA. 2011. $\mathrm{Ca}^{2+}$ signaling during mammalian fertilization: Requirements, players, and adaptations. Cold Spring Harb Perspect Biol 3: a006767.

Wolf FI, Trapani V. 2012. Magnesium and its transporters in cancer: A novel paradigm in tumour development. Clin Sci (Lond) 123: $417-427$.

Wong W, Scott JD. 2004. AKAP Signalling complexes: Focal points in space and time. Nat Rev Mol Cell Biol 5: 959-971.

Wu J, Sun L, Chen X, Du F, Shi H, Chen C, Chen ZJ. 2013. Cyclic GMPAMP is an endogenous second messenger in innate immune signaling by cytosolic DNA. Science 339: 826-830.

Wymann MP, Schneiter R. 2008. Lipid signalling in disease. Nat Rev Mol Cell Biol 9: 162-176. 


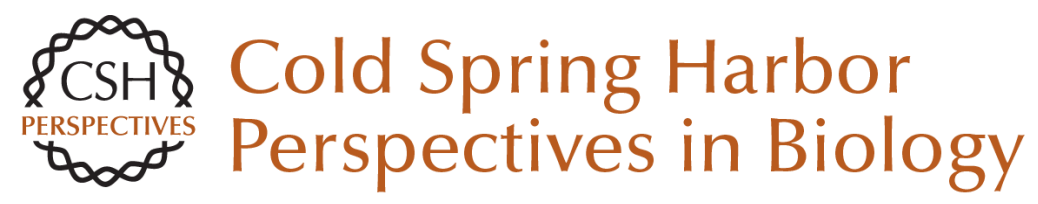

\section{Second Messengers}

Alexandra C. Newton, Martin D. Bootman and John D. Scott

Cold Spring Harb Perspect Biol 2016; doi: 10.1101/cshperspect.a005926

Subject Collection Signal Transduction

Cell Signaling and Stress Responses Gökhan S. Hotamisligil and Roger J. Davis

Protein Regulation in Signal Transduction Michael J. Lee and Michael B. Yaffe

Synaptic Signaling in Learning and Memory Mary B. Kennedy

Vertebrate Reproduction Sally Kornbluth and Rafael Fissore

Signaling in Lymphocyte Activation Doreen Cantrell

Signaling in Muscle Contraction Ivana Y. Kuo and Barbara E. Ehrlich

Toll-Like Receptor Signaling Kian-Huat Lim and Louis M. Staudt

Signaling Pathways that Regulate Cell Division Nicholas Rhind and Paul Russell
Second Messengers

Alexandra C. Newton, Martin D. Bootman and John D. Scott

Signals and Receptors Carl-Henrik Heldin, Benson Lu, Ron Evans, et al.

Cell Death Signaling Douglas $R$. Green and Fabien Llambi

Signaling Networks that Regulate Cell Migration Peter Devreotes and Alan Rick Horwitz

Signaling Networks: Information Flow, Computation, and Decision Making Evren U. Azeloglu and Ravi lyengar

Signal Transduction: From the Atomic Age to the Post-Genomic Era Jeremy Thorner, Tony Hunter, Lewis C. Cantley, et al.

Signaling by the TGF $\beta$ Superfamily Jeffrey L. Wrana

Subversion of Cell Signaling by Pathogens Neal M. Alto and Kim Orth

For additional articles in this collection, see http://cshperspectives.cshlp.org/cgi/collection/

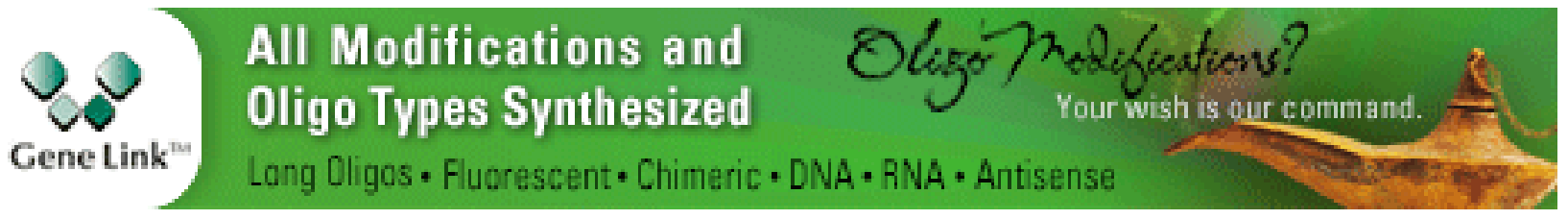

Copyright @ 2016 Cold Spring Harbor Laboratory Press; all rights reserved 